\title{
Assessing the environmental impacts of 2nd generation (lignocellulosic) feedstock under the energy-climate reference scenario using LUISA modelling platform in EU-28
}

\author{
C. Perpiña Castillo, C. Lavalle, C. Baranzelli, A. Barbosa, \\ C. Jacobs-Crisioni \& F. Batista e Silva \\ European Commission, Joint Research Centre, \\ Institute for Environment and Sustainability, Italy
}

\begin{abstract}
In this study a comprehensive analysis of the environmental impacts of $2^{\text {nd }}$ generation (lignocellulosic) feedstock using LUISA (Land Use Integrated Sustainability Assessment) spatial modelling platform has been performed under the Energy-Climate reference scenario in EU-28 from 2010 up to 2050. The definition of this reference scenario and its implementation in LUISA is described in this paper, emphasizing the role of the renewable energy directive in the promotion of renewable energies under sustainability criteria for the biomass production, including energy crops. These sustainability criteria attempt to minimize the potential negative impacts on environment, social and economic aspects. Accordingly, site selection is a crucial step, taking into account the ecological requirements of herbaceous and woody lignocellulosic crops for energy purpose. Geographical areas characterised by high suitability levels for the cultivation of energy crops were identified and mapped. A possible solution to land competition conflict is the use of degraded and potentially contaminated lands for growing energy lignocellulosic crops in those areas. The main output from LUISA over the allocation of energy crops are displayed and analysed in detail. Keywords: energy crops, modelling, allocation, European Union, sustainability.
\end{abstract}




\section{Introduction}

The work presented in this report is an application of the Land Use Integrated Sustainability Assessment platform (LUISA) based on the Energy Climate Package under a Reference Scenario defined as specified in the Energy Trends to 2030 [1], as well as the Roadmap itself [2].

The Climate and Energy legislative package adopted in December 2008 established different measures to mitigate climate change and promote renewable energy [3]. This package is designed to achieve the EU's overall environmental target by 2020: 20\% reduction in greenhouse gas emissions from 1990 levels, 20\% share of renewable energy in the EU's total energy consumption and a $20 \%$ improvement in EU's energy efficiency. An important role in this context plays the Renewable Energy Directive (RED) aim at promoting the use of renewable sources for the energy and transport sectors (2009/28/EC) [4].

In this study energy crops are hereinafter regarded as non-food, lignocellulosic crops, belonging to the so-called category of $2^{\text {nd }}$ generation feedstock. They have been considered as perennial energy crops that are grown specifically for their fuel value [5]. Broadly speaking, lignocellulosic crops generally fall into two categories: herbaceous and woody crops (Short rotation coppice) [5-8]. In the LUISA configuration, the herbaceous lignocellulosic crops considered are: Miscanthus (Miscanthus spp.), Switchgrass (Panicum virgatum), Reed canary (Phalaris arundinacea), Giant reed (Arundo donax) and Cardoom (Cynara cardunculus). In the case of woody lignocellulosic, the tree crops considered are: Willow (Salix spp.), Poplar (Populus spp.) and Eucaliptus (Eucaliptus spp.).

According to the RED, sustainability criteria to minimize the potential negative impacts on environmental (biodiversity, soil, climate change, water, air quality and resource use), social (land competition and labour conditions) and economic aspects (bioenergy costs) must be taken into account for the production of biomass for energy uses. Most of the criteria listed in the RED were included in the modelling configuration of LUISA, and specifically: restriction on protected areas and with high biodiversity value, restriction on land with high carbon stock (forest, wetlands and peatlands), preference of using superplus lands (degraded and abandoned lands), maximum slope limits for cultivation, on sites susceptible to soil erosion only perennial crops can be grown, adapt management practices (crop choice and yields) to local biophysical conditions, among others [5].

\section{An overview of LUISA modelling platform}

\subsection{Structure, applications and policies in LUISA}

LUISA is a dynamic, spatial modelling platform based on biophysical and socioeconomic drivers. The platform has been developed to assess land use impacts of European policies by providing a vision of possible futures and quantitative comparisons between policy options. LUISA simulates future land use changes; land functions related to the resulting land use patterns are then inferred and described by means of spatially explicit indicators [9]. 
LUISA has been employed in a number of different policy assessments projects, which the scope and goals of those projects varies substantially. It reveals the breadth of topics where land-use impacts are relevant as well as the flexibility of the LUISA platform. Some of these applications are: impacts of policy alternatives for coastal zone management, impact of the green measures of CAP (Common Agricultural Policy), water blueprint project, impacts of shale gas development in Europe, resource efficiency in Europe, assessing the direct and indirect land-use impacts of the Cohesion Policy, assessment of ecosystem services among others.

LUISA is structured in three main modules (figure 1): the 'demand module', the 'land use allocation module' and 'the indicator module' [10,11]. The demand module receives direct input from several external macroeconomic models: EUROPOP for population [12], GEM-E3 [13] for industry and commerce, CAPRI [14], for agricultural commodities (production of food, feed and energy crops), and GLOBIOM/G4M [15] for forestry. The allocation module spatially distributes the regional land use demands to $100 \mathrm{~m}$ pixel resolution considering biophysical characteristics, neighbourhood factors, the competition for land and policy-based restrictions. The main final output of the allocation module is a time series of yearly land use map, from 2007 to for the EU28. The indicator module addresses the impact of the policy measures implemented upstream according to the goal of the analysis The assessment under the reference scenario presented in this document refers mainly to the impact of the EU policies on energy production from $2^{\text {nd }}$ generation feedstock (energy crops) at regional level.

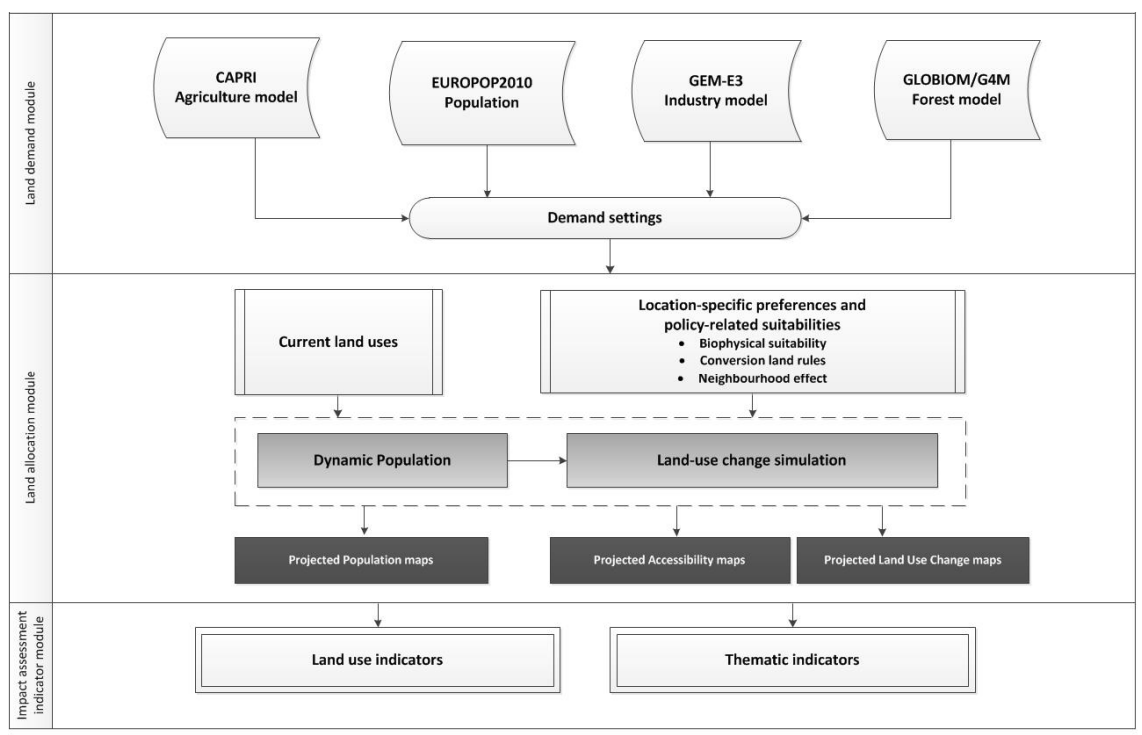

Figure 1: Modular structure of LUISA and the main models and dataset included. 


\section{Energy crops allocation and exploitation of soil fertile land from LUISA}

In this section, the simulated allocation of energy crops is analysed in detail in three different fashions: share of energy crops over the total land available for their cultivation; total acreage of planted energy crops; and quantity of energy crops cultivated on different classes of fertile land. Results are aggregated at three geographical levels: country, region (NUTS2) and province (NUTS3).

\subsection{Energy crop allocation at European and regional scale}

According to the LUISA's simulation results, energy crops in EU28 occupy 8,532 and 15,126 kha in 2030 and 2050 respectively. It represents over 3.1\% and 5.9\% of Europe's total available land area, respectively. As figure 2 shows, the EU average is $355 \mathrm{kha}$ and $630 \mathrm{kha}$ in 2030 and 2050, respectively. This translates in an increase of $77 \%$ between 2030 and 2050, but with a significant variability between Member States. Poland, France, Germany, Spain, Romania and the United Kingdom are the countries that contribute the most, in terms of acreage, to the production of energy crops, accounting all together for $80 \%$ of the European acreage. In the final year of the simulation (2050), the availability of energy crops reaches up to more than 3,000 kha (Poland), whereas the tiniest presence is below 100 kha (Luxembourg, Bulgaria, Belgium, Slovenia, the Netherlands and Portugal). It must be noted that, according to the CAPRI model projections, energy crops are not forecasted to be introduced in Denmark, Greece, Croatia, Malta and Cyprus.

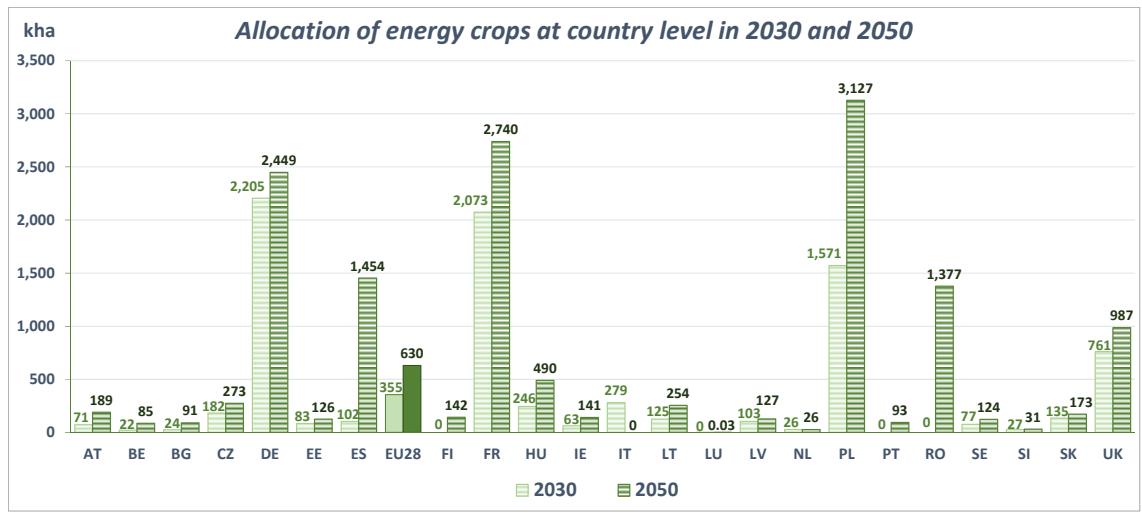

Figure 2: Amount of land, expressed in thousands of hectares, occupied by energy crops on available land, at county level, for the years 2030 and 2050 in EU 28. Country values are represented by striped background; solid background indicates the European average.

As shown in figure 3, the allocation of energy crops is globally projected to increase in Europe. The European average is approximately $2.8 \%$ and $4.2 \%$ in 
2030 and 2050, respectively. In only few regions the share of allocated energy crops over the available land exceeds $10 \%$. One example is the region of Cheshire in the United Kingdom, which reaches $14.6 \%$ and $17.7 \%$ in 2030 and 2050 respectively. Despite the fact that the number of regions above $10 \%$ share is higher in 2050, most of these regions belongs to Poland; other can be found in the United Kingdom and Germany.

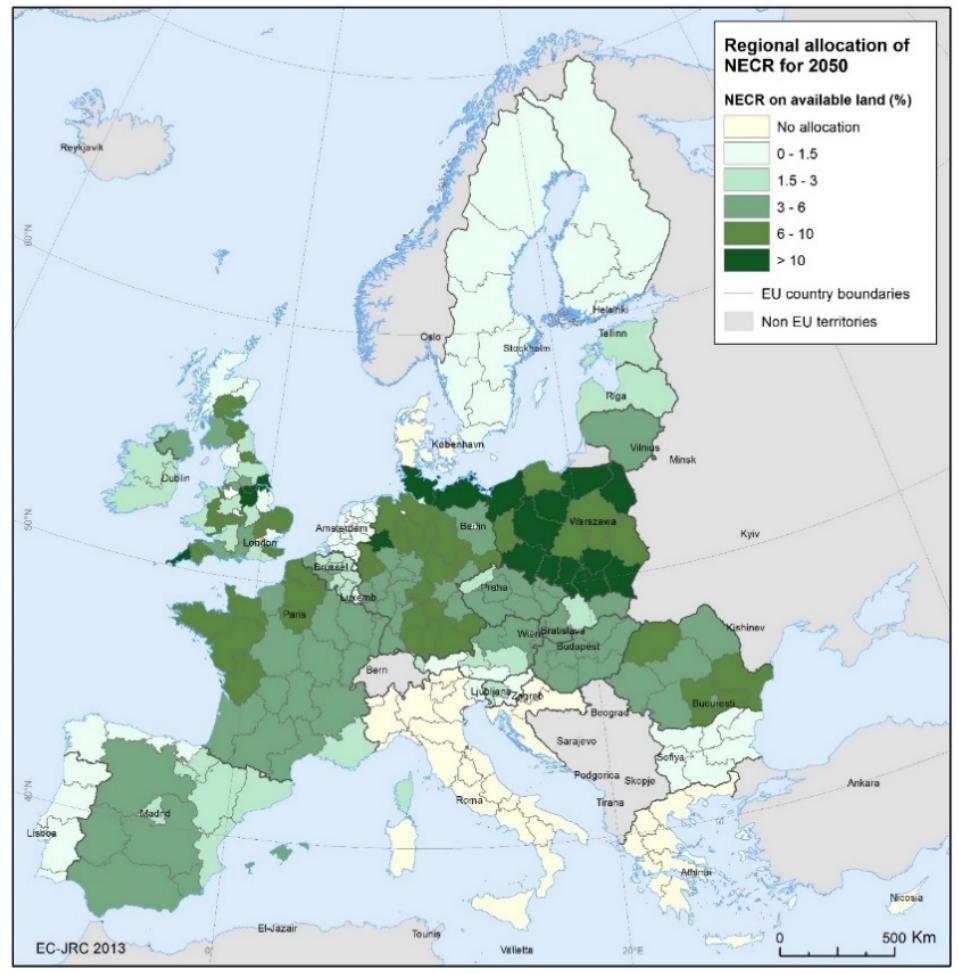

Figure 3: Share of allocated of energy crops on available land, at NUTS2 level for the year 2050 in EU-28.

Local differences regarding the allocation patterns of energy crops at NUTS3 level are mainly due to the total amount of available land within each province (figure 4). On the other hand, energy crops are encouraged to occupy areas with unfavourable biophysical characteristics, such as degraded and contaminated lands (see section 3.3). In 2020 and 2030, Germany shows the highest number of provinces with energy crops production above $50 \%$ on available land. These same German provinces keep a stable share of allocated energy crops in 2040 and 2050. Some provinces in Poland and the United Kingdom show a similar behaviour. On the contrary, minimum production of energy crops is mostly located in Sweden, Finland, Slovenia, Bulgaria, Latvia, Estonia, Austria and Portugal, where the share of allocated energy crops does not reach $1 \%$ in any province. 


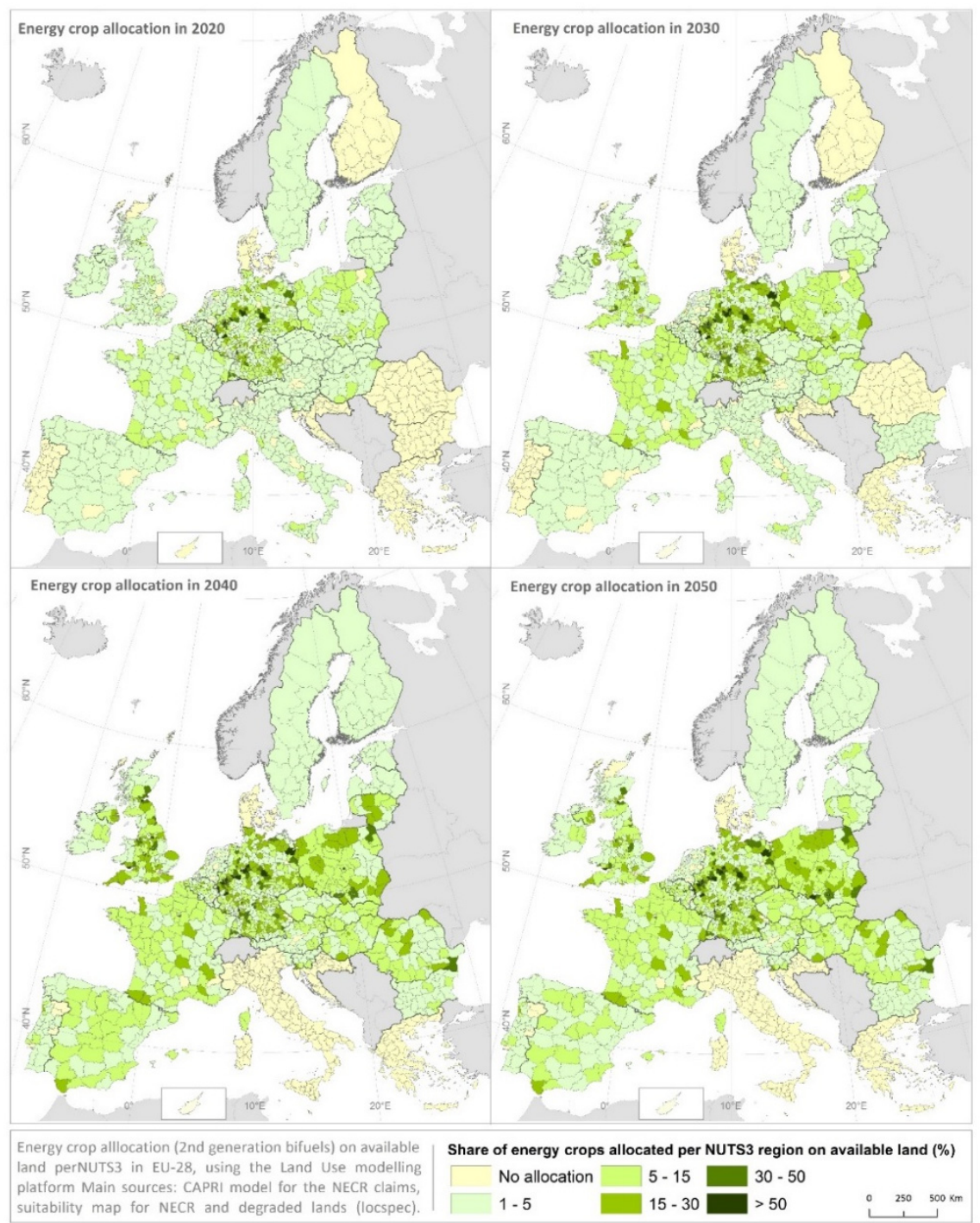

Figure 4: Share of the allocated energy crops on available land, per NUTS3 region, for the years 2020, 2030, 2040 and 2050.

The absolute amount of cultivated energy crops offer a different picture, if compared to the shares described in the first part of this section. The land occupied by energy crops is expressed in ha, for the years 2030 and 2050. In 2030, France is by far the European country that counts the vastest surface dedicated to energy crop production, reaching more than 182,000 ha in the Pays de la Loire, followed by Poland with 176,000 ha allocated in the Mazowieckie region, and Germany with approximately 158,000 ha cultivated in the Brandenburg region. Many of 
remaining countries show a quite homogeneous pattern at NUTS2 level, with most of their regions falling into the first group of the ranking, up to 25,000 ha. In 2050 (figure 5), the highest amount of land allocated to energy crops can be found not only in Poland, Germany and France, but also in Romania and Spain.

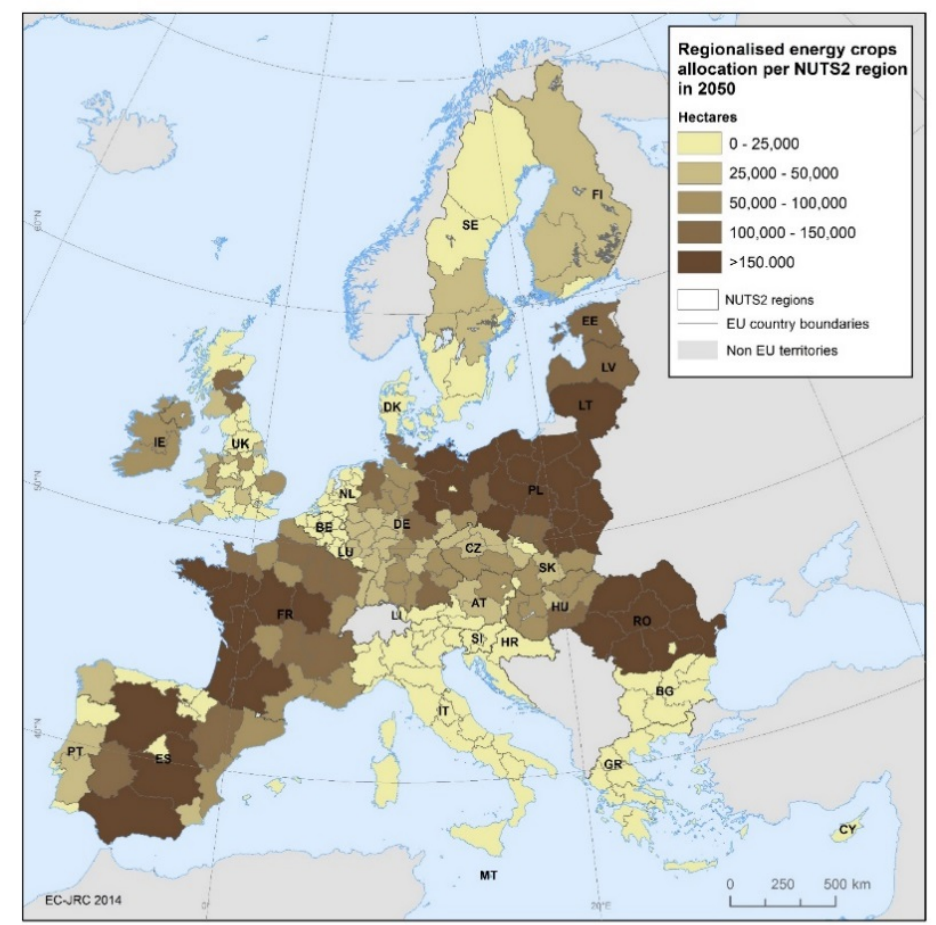

Figure 5: Total availability of energy crops, expressed in hectares, at NUTS2 level, in 2050.

\subsection{Allocation of energy crops according to biophysical suitability levels}

In this section, allocated energy crops are classified according to the local biophysical conditions where these crops might be grown referred to as 'suitability levels' (very low, low, moderate, high and very high). The higher the suitability, the higher the potential productivity level (yield), thus reducing the need of additional inputs potentially harmful to the environment. Figure 6 reports how many hectares of energy crops have been successfully allocated in the most suitable areas in EU, providing an overview at regional scale for the years 2030 and 2050. In 2050, energy crops are predominantly allocated on very high and high suitability levels in the central and south part of France, north of Spain, Portugal, few regions in Bulgaria and Hungary. In entire countries like The Netherlands, Belgium, Luxembourg and Ireland, and numerous regions in United Kingdom, Spain, Bulgaria, Romania and Germany, energy crops are mainly 
allocated on moderately suitable land. Allocation on low and very low levels is mainly predominant in regions of the central and eastern part of Europe, and in Finland and Sweden. In 2050, the allocation of energy crops on moderate, high and very high suitability levels $(35.5 \%, 10.3 \%$ and $2.6 \%$ respectively) increases to $48 \%(6,982$ kha in total) with respect to 2030 .

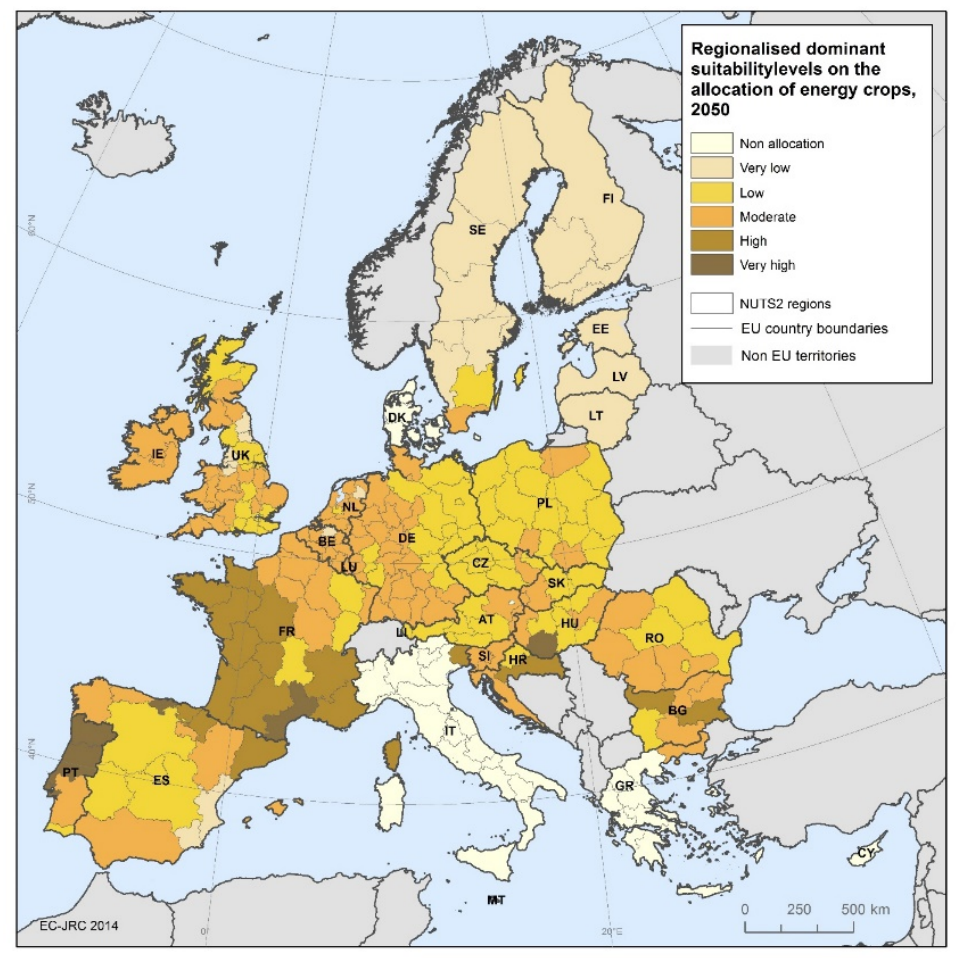

Figure 6: Suitability level on which the majority of energy crops, at NUTS2 level, are allocated in the year 2050.

In order to fulfil the sustainability criteria introduced by the RED and to avoid competition with other conventional agricultural crops, a possible solution is the use of degraded, low productivity lands and potentially contaminated lands for growing energy crops, as discussed in the following section.

\subsection{Use of degraded and contaminated lands for energy crops allocation}

Within the scope of the present article, degraded lands are referred to as lands with a decrease on current and/or future capacity of the soil to support human life [5]. EU-specific policies applied to $2^{\text {nd }}$ generation lignocellulosic feedstock must be considered in order to convert different land uses to energy production purposes. As food production needs good quality soils, the reclamation of degraded and contaminated lands can offer additional positive implications to planting energy 
crops in those areas. Soil salinity, severe erosion areas and contaminated lands have been selected as unfavourable agriculture soil conditions [16-20]. In fact, some of the selected lignocellulosic species have particular ecological properties that allow them to be grown in such affected/degraded soils. The amount of land allocated for each category of unfavourable agriculture soil conditions is aggregated at NUTS2 level. In 2030, the share of energy crops allocated on degraded and contaminated lands varies strongly across NUTS2 regions of the Member States. High proportions of energy crops allocated on degraded land can be mostly found in some parts of Italy, Spain, France, Belgium and the United Kingdom, reaching more than $45 \%$ in 2030. In 2050, the overall picture for Europe is similar to 2030; main differences can be found in Portugal, .which shows high shares and previously had no allocated energy crops; and Italy, whereby energy crops are no longer present in 2050.

\subsection{Assessment at regional level of the energy crop allocation}

Further development at regional level (NUTS2) are there presented for each Member State, exemplified by Spain (figure 7). Analysing the results, it is possible to group Member States under two main profiles:

Countries in which the availability of energy crops is considerably high and the exploitation of low productivity lands might be high or low. France, Germany, United Kingdom and Poland, with high production and high use of degraded and contaminated lands, belong to this first profile. In these countries, $15 \%$ of low productivity lands are used by energy crops on available land. In the particular cases of Spain and Romania, the figures show worst results: the allocation on degraded lands is about $1.6 \%$ and below one percentage point, respectively. In addition, Germany, United Kingdom and Poland allocate energy crops on low, very low and moderate biophysical suitability levels, which means that more inputs might be needed for the production. On the contrary, France, Spain and Romania have a better distribution among the moderate, high and very high suitability levels. The projected allocation of energy crops implies the conversion from other land uses, and for these high producer countries, mainly other arable land and cereals suffer the higher losses.

Countries in which the availability of energy crops is moderate or considerably low, and the usage of low productivity lands might be high or low. In the first case, with moderate production and high use of degraded and contaminated lands, Austria is the only country with a high reconversion of low productivity lands, nearly 8\%. Other countries, such as Bulgaria, Czech Republic, Estonia, Finland, Hungary, Lithuania, Latvia, Luxembourg, Portugal and Sweden, are moderate and low producers respectively, and low user of degraded and contaminated lands (below 1\%). In the particular case of Belgium, Ireland, Italy, The Netherlands, Slovakia and Slovenia, the figures show better results: the allocation on low productivity land is $3 \%$ on average. With the exception of Bulgaria, Hungary, Italy, Portugal, and Slovenia, where energy crops have a better spreading among the moderate, high and very high suitability levels, the remaining countries allocated energy crops on low, very low and moderate biophysical suitability levels. 


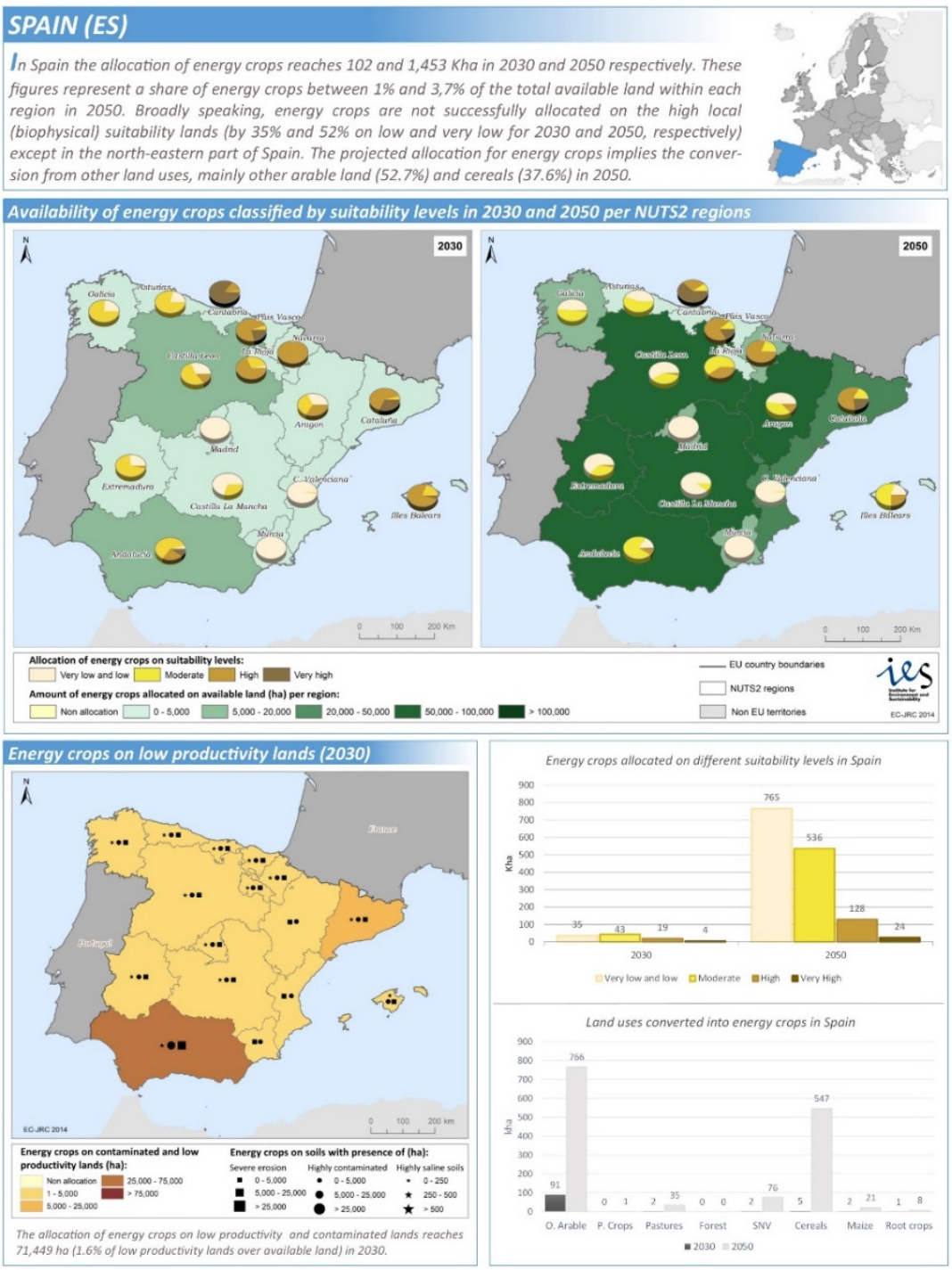

Figure 7: Example of a factsheet for France, reporting the allocation of energy crops per suitability levels and on low productivity land, 2030 and 2050 .

\section{Conclusions}

LUISA (Land Use Integrated Sustainability Assessment) modelling platform allows for simulating the allocation of different land uses simultaneously, taking into account all the relevant policy constraints and incentives that have a direct impact on the spatial distribution of such uses. At the same time LUISA allocation 
mechanism are based on spatial explicit suitability criteria, mainly related to biophysical characteristics, neighbourhood effects and conversion rules between the simulated land uses.

In the current modelling exercise, and in compliance with the CAPRI model specifications, energy crops are referred to as non-food, lignocellulosic crops, belonging to the so-called category of $2^{\text {nd }}$ generation feedstock for energy production. Energy crops have been analysed with respect to the level of soil quality (suitability) where they have been allocated. Overall, it can be stated that growing energy crops on high biophysically suitable land results in a reduction of water consumption, inputs use, such as fertilizers and pesticides, thus minimising the associated negative environmental impacts. Moreover, the reclamation of degraded and contaminated lands to planting energy crops can offer additional positive implications with the main purpose to avoid land competition with other conventional agricultural crops. Soil salinity, severe erosion areas and contaminated lands have been selected as unfavourable agriculture soil conditions.

According to LUISA's simulation results, energy crops in EU28 occupy 8,532 and 15,126 kha in 2030 and 2050 respectively It represents over 3.1\% and 5.9\% of Europe's total available land area, respectively. Poland, France, Germany, Spain, Romania and United Kingdom are the countries that contribute the most to the production of energy crops. Concerning the simulations of energy crops allocated on unfavourable agricultural soil conditions (high salinity areas, severe erosion, highly contaminated areas by heavy metals) can be mostly found in some parts of Italy, Spain, France, Belgium and the United Kingdom.

\section{References}

[1] EC (European Commission). 2009a. EU energy trends to 2030. European Commission. Directorate General for Energy in collaboration with Climate Action DG and Mobility and Transport DG.

[2] EC, 2011. European Commission, COM (2011) 885 final. Results of the public consultation on the "Energy Roadmap 2050". Brussels, 15.12.2011.

[3] Council of the European Union, 2008. Energy and climate changes element of the final compromise (17215/08). Brussels, 12 December 2008.

[4] EC (European Commission) 2009b. European Commission. Directive 2009/28/EC of the European Parliament and of the Council on the use of energy from renewable sources and amending and subsequently repealing Directives 2001/77/EC and 2003/30/EC.

[5] Biomass Energy Europe (BEE) project, 2010. European Commission. Framework Programme 7.

[6] Fischer, G., Prieler, S., Van Velthuizen, H., Lensink, S.M., Londo, M., De Wit, M., 2010a. Biofuel production potentials in Europe: Sustainable use of cultivated land and pastures. Part I: Land productivity potentials. Biomass and Bioenergy, 34, 159-172.

[7] UNICT (Università degli Studi di Catania Future), 2009. Crops for Food Feed, Fiber and Fuel (4F Crops). WP2 - Task 2.1. Choice of the crops. Task 2.6. Cropping possibilities. Dipartimento Scienze Agronomiche, 
Agrochimiche e delle Produzioni Animali, Italy. (Seventh framework programme).

[8] DEFRA (Department for Environment, Food and Rural Affairs), 2004. Best practice guide lands. Growing Short Rotation Coppice. For applicants to DEFRA'S Energy Crops Scheme. England.

[9] Lavalle, C., Mubareka, S., Perpiña Castillo, C., Jacobs-Crisioni, C., Baranzelli, C., Batista e Silva, F., Vandecasteele, I., 2013. Configuration of a Reference Scenario for the Land Use Modelling Platform. JRC Scientific and Technical Reports. ISBN 978-92-79-32349-2.

[10] Batista e Silva F, Lavalle, Jacobs-Crisioni, Barranco R, Zulian G, Maes J, Baranzelli C, Perpiña C, Vandecasteele I, Ustaoglu E, Barbosa A, Mubareka S (2013). Direct and Indirect Land Use Impacts of the EU Cohesion Policy. Assessment with the Land Use Modelling Platform. EUR 26460.

[11] Lavalle, C., C. Baranzelli, F. Batista e Silva, S. Mubareka, C. Rocha Gomes, E. Koomen, and M. Hilferink. 2011. A High Resolution Land use/cover Modelling Framework for Europe: introducing the EU-ClueScanner100 model. In Computational Science and Its Applications - ICCSA 2011, Part I, Lecture Notes in Computer Science vol. 6782.

[12] EUROSTAT. 2010. EUROPOP2010 - Convergence scenario, national level. http://epp.eurostat.ec.europa.eu/cache/ITY_SDDS/EN/proj_10c esms.htm.

[13] GEM-E3 (General Equilibrium Model for Economy - EnergyEnvironment), 2012. Webpage: https://ec.europa.eu/jrc/en/gem-e3/model.

[14] Britz, W., Witzke, H. P., 2012. Capri model documentation 2012: Version 2. Bonn: Institute for Food and Resource Economics, University of Bonn.

[15] IIASA (International Institute for Applied Systems Analysis), 2012. Globiom and G4M model. http://webarchive.iiasa.ac.at/Research/FOR/ globiom/forestry.html.

[16] FAO/IIASA/ISRIC/ISSCAS/JRC, 2012. Harmonized World Soil Database (version 1.2). FAO, Rome, Italy and IIASA, Luxemburg, Austria. http://webarchive.iiasa.ac.at/Research/LUC/External-World-soildatabase/HTML/index.html?sb=1.

[17] EC (European Commission), 2013a. Joint Research Centre. European Soil Portal - Soil data and information system. Data for the Soil Information System for the MARS Crop Yield Forecasting System (SINFO). http://eusoils.jrc.ec.europa.eu/library/data/sinfo/.

[18] EC (European Commission), 2013b. Joint Research Centre. European Soil Database. http://eusoils.jrc.ec.europa.eu/ESDB_Archive/ESDB_data_1k raster_intro/ESDB_1k_raster_data_intro.html.

[19] Micó, $\bar{C}$., Peris, M., Recatalá, L., Sánchez, L., 2007. Baseline values for heavy metals in agricultural soils in a European Mediterranean region. Science of the total environment, 378, 13-17.

[20] Lado, R., Hengl, T., Reuter, H.I., 2008. Heavy metals in European soils: a geostatistical analysis of the FOREGS Geochemical database. Geoderma, 148, 189-199. 